\title{
Towards new NIR dyes for free radical photopolymerization processes
}

\author{
Haifaa Mokbel ${ }^{1,2}$, Guillaume Noirbent ${ }^{3}$, Didier Gigmes ${ }^{3}$, Frédéric Dumur ${ }^{*} 3$ \\ and Jacques Lalevée*1,2
}

Open Access

\author{
Full Research Paper \\ Address: \\ ${ }^{1}$ Université de Haute-Alsace, CNRS, IS2M UMR 7361, F-68100 \\ Mulhouse, France, ${ }^{2}$ Université de Strasbourg, France and ${ }^{3} \mathrm{Aix}$ \\ Marseille Univ, CNRS, ICR UMR 7273, F-13397 Marseille, France \\ Email: \\ Frédéric Dumur - Frederic.dumur@univ-amu.fr; Jacques Lalevée* - \\ jacques.lalevee@uha.fr \\ * Corresponding author \\ Keywords: \\ cyanine; NIR light; photochemistry
}

Beilstein J. Org. Chem. 2021, 17, 2067-2076.

https://doi.org/10.3762/bjoc.17.133

Received: 15 June 2021

Accepted: 06 August 2021

Published: 16 August 2021

Associate Editor: H. Ritter

(c) 2021 Mokbel et al.; licensee Beilstein-Institut. License and terms: see end of document.

\begin{abstract}
The use of cheap and safe near-infrared (NIR) light is still the subject of intense research efforts but remains a huge challenge due to the associated low photon energy (wavelength from 0.78 to $2.5 \mu \mathrm{m}$ ). In this study, a series of 17 NIR dyes mainly based on a well-established cyanine scaffold is proposed. Remarkably, 11 of them were never synthesized before. Markedly, noncharged structures, negatively charged cyanine bearing $\mathrm{Na}^{+}$as counter cation, and positively charged cyanines bearing $\left(\mathrm{B}(\mathrm{Ph})_{4}^{-}\right)$or $\left(\mathrm{I}^{-}\right)$as counter anions were examined as promising NIR light photoinitiating systems. Excellent photoinitiating abilities were found for some reported dyes when used in combination with iodonium salt and amine. Markedly, photothermal effects with a huge heater behavior were also observed for different NIR dye structures. Interestingly, the synthesis of interpenetrating polymer networks (IPNs, e.g., for the polymerization of acrylate/epoxy monomer blends) can also be carried out upon NIR light with the proposed systems.
\end{abstract}

\section{Introduction}

Photopolymerization processes are well established due to the specific features and advantages. Indeed, the reaction is carried out at room temperature and with a high spatial resolution (the reaction only occurs in the light-irradiated areas). These latter photochemical processes are also very fast and efficient. However, energetic and unsafe UV light is usually used to ensure high polymerization rates and final reactive function conversions. To prevent the use of harmful UV light, different longer-wavelength photoinitiating systems (PISs) were proposed, e.g., blue light in dental materials [1,2]. Many PISs were developed for visible light, but much less studies are focused on the polymerization using 
near-Infrared (NIR) sources [3-8]. In this context, the use of NIR light is very attractive, i.e., such a long wavelength is quite safe and characterized by an excellent penetration in materials. Interestingly, NIR curing technology exhibit several advantages: i) an efficient process: a high polymerization rate obtained with low energy and a moderate device cost contrary to thermal solutions; ii) mild irradiation conditions: safer and cheaper systems; and iii) the curing of thick and/or filled systems that cannot be addressed with UV or even visible-lightsensitive systems. Thus, the NIR curing of thick and filled samples can be potentially used for composite materials and/or adhesives.
Both photochemical and photothermal NIR approaches were proposed to initiate polymerization, e.g., for free-radical processes, interpenetrating polymer network (IPN) synthesis, or photopolyaddition reactions [3,4,6-9]. NIR dyes, and more especially cyanine dyes, have been studied in NIR photosensitive systems [5-7,9-15]. The cyanine acts as a photosensitizer: it absorbs the light emitted in the NIR range and then acts with a combination of additives (oxidant agents and reducing agents) to generate initiating radicals.

In this work, a large series of 17 NIR dyes mainly based on a well-established cyanine scaffold is proposed (Scheme 1).

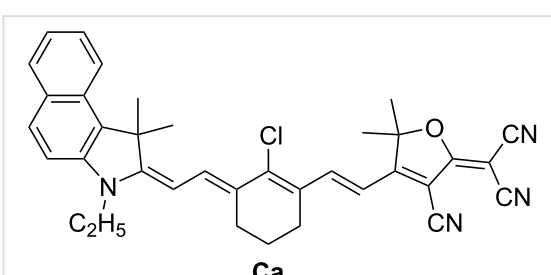

$\mathrm{Ca}$

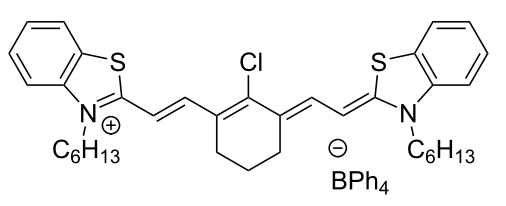

CBPh1
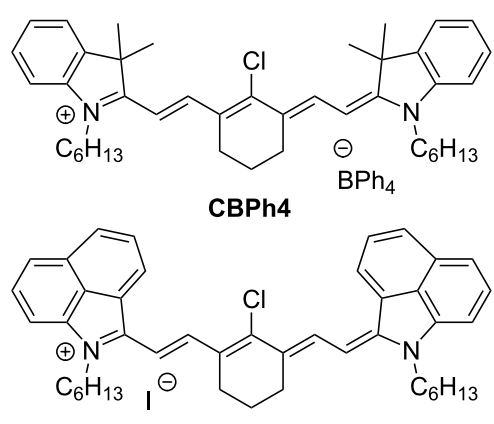

$\mathrm{Cl3}$

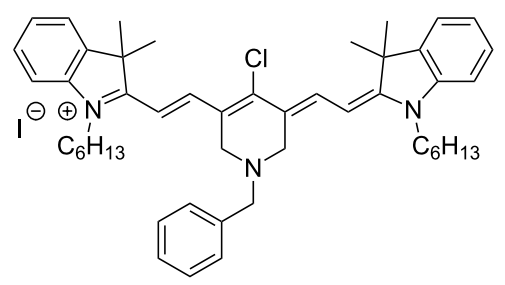

Cl6<smiles>CN1/C(=C/C=C2\CCCC(/C=C/C3=C(C#N)C(=C(C#N)C#N)OC3(C)C)=C2Cl)C(C)(C)c2c1ccc1ccccc21</smiles>

$\mathrm{Cb}$<smiles></smiles>

$\mathrm{CBPh} 2$

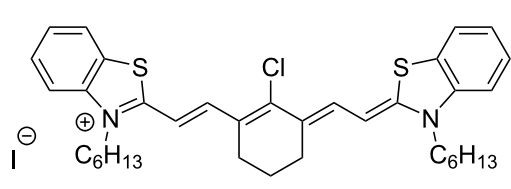

Cl1<smiles>CCCCCCN1C(=CC=C2CCCC(C=CC3=C(C)C(C)(C)c4ccccc43)=C2Cl)C(C)(C)c2ccccc21</smiles>

Cl4

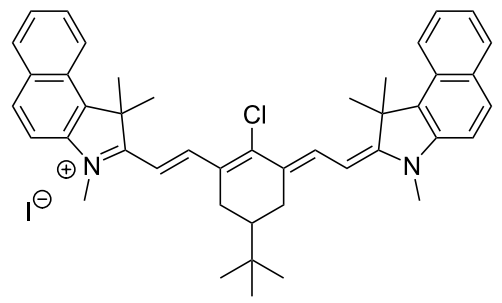

$\mathrm{Cl} 7$

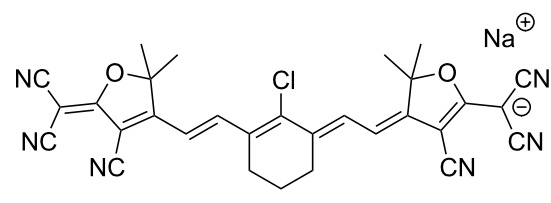

$\mathrm{CNa}$

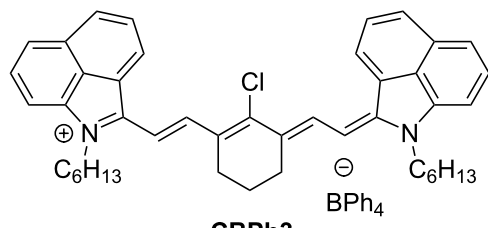

CBPh3

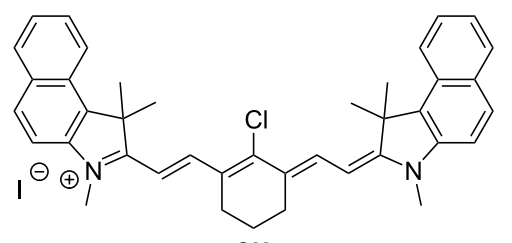

$\mathrm{Cl} 2$
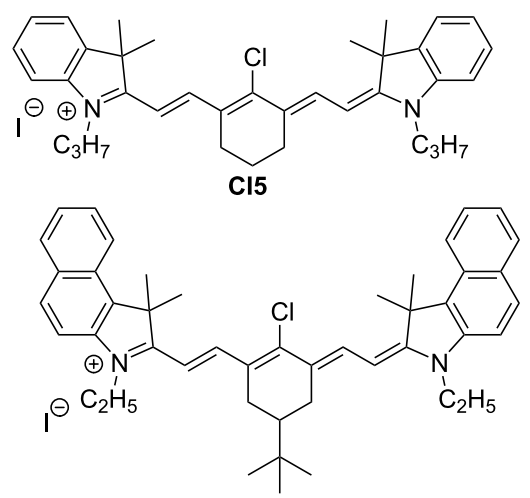

$\mathrm{Cl} 8$

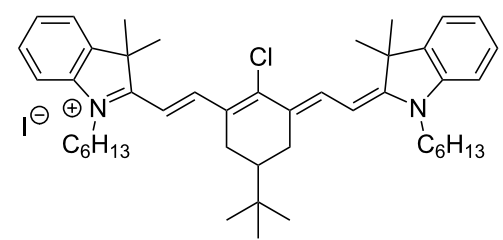<smiles></smiles>

Cl9 
Markedly, eleven of them were never synthesized before. These NIR dyes are studied in three-component systems in combination with an iodonium salt and the tertiary aromatic amines 3-(dimethylamino)benzyl alcohol (DABA) and $N$-phenylglycine (NPG), respectively, for the polymerization of a benchmark monomer (PETIA, Scheme 2). The polymerization profiles were recorded by real-time Fourier transform infrared spectroscopy (FTIR, the procedure is described in detail in [16]). Interestingly, a high polymerization-initiating ability was found with different dyes as well as photothermal effects with heater behaviors where the NIR dye acts as a light-to-heat convertor and transferred enough heat to the system to initiate the polymerization. The effects of counter anions and counter cations as well as cyanine structures are discussed.

\section{Results and Discussion}

\section{Synthesis of the different dyes}

Two different families of cyanines were prepared, differing by the way how the structure is formed. Notably, dyes $\mathbf{C a}$ and $\mathbf{C b}$ differ from the other cyanines by the asymmetric substitution. Thus, in the first step, the Claisen-Schmidt condensation of 2-chloro-3-(hydroxymethylene)cyclohex-1-ene-1-carbaldehyde on 2-(3-cyano-4,5,5-trimethylfuran-2(5H)-ylidene)malononitrile (TCF) furnished the intermediate 2-(4- $((E)-2-((E)-2-$ chloro-3-(ethoxymethylene)cyclohex-1-en-1-yl)vinyl)-3-cyano5,5-dimethylfuran-2(5H)-ylidene)malononitrile in $65 \%$ yield. A second Claisen-Schmidt condensation of 2-(4- $((E)-2-((E)-2-$ chloro-3-(ethoxymethylene)cyclohex-1-en-1-yl)vinyl)-3-cyano-
5,5-dimethylfuran-2(5H)-ylidene)malononitrile with the appropriate 3-alkyl-1,1,2-trimethyl-1H-benzo[ $e]$ indol-3-ium salt under basic conditions could furnish the two dyes $\mathbf{C a}$ and $\mathbf{C b}$ in $89 \%$ and $94 \%$ yield, respectively. Conversely, the anionic TCFbased heptamethine $\mathbf{C N a}$ was prepared under slightly different conditions, using sodium acetate in acetic anhydride. After one hour of reaction, compound $\mathbf{C N a}$ could be isolated in $82 \%$ yield (Scheme 3).

Due to the symmetrical substitution of the other dyes, a onestep procedure could be used for the synthesis of the pentamethine cyanine dyes. It has to be noticed that the present series of pentamethine dyes was prepared using synthetic protocols inspired by the literature. However, when dyes with already existing substitutions were reproduced in this work, original substitutions are also described, as exemplified with compound CI6. Indeed, for this compound, use of a central part derived from 1-benzylpiperidin-4-one is unprecedented in the literature. Similarly, among the seven symmetrical pentamethine dyes synthesized in this work, only dyes CI8 [17] and CI9 [18] were previously reported in the literature. For all the other dyes, judicious choice of the alkyl chains introduced to the peripheral groups resulted in previously unknown compounds. All dyes could be obtained with a reaction yield ranging from $66 \%$ to 91\% (Scheme 4).

Finally, for some of the dyes, a metathesis reaction was carried out with sodium tetraphenylborate. Indeed, all dyes were ob-
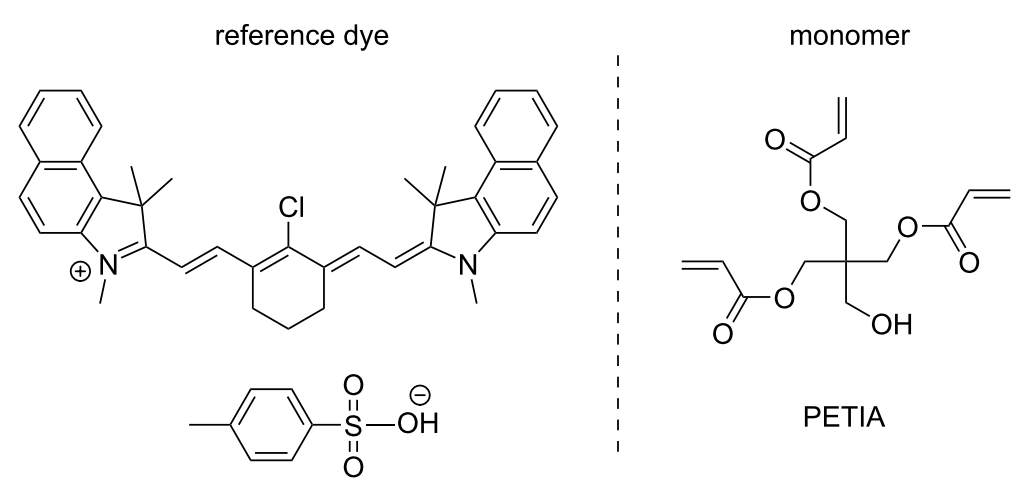

cationic photoinitiator<smiles>CC(C)(C)c1ccc([Te]c2ccc(C(C)(C)C)cc2)cc1</smiles>

iodonium salt (ion)

sacrificial amines<smiles>O=C(O)CNc1ccccc1</smiles>

NPG<smiles>CN(C)c1cccc(CO)c1</smiles>

DABA 
<smiles>CCO/C=C1/CCCC(/C=C/C2=C(C#N)C(=C(C#N)C#N)OC2(C)C)=C1Cl</smiles><smiles>CCO/C=C1\CCCC(/C=C/C2=C(C#N)C(=C(C#N)C#N)OC2(C)C)=C1Cl</smiles>

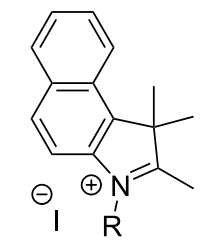

with $\mathrm{R}=\mathrm{Me}, \mathrm{Et}$<smiles>[R]N1/C(=C/C=C2\CCCC(/C=C/C3=C(C#N)C(=C(C#N)C#N)OC3(C)C)=C2Cl)C(C)(C)c2c1ccc1ccccc21</smiles>

Ca: $\mathrm{R}=\mathrm{Et}, 89 \%$ yield

Cb: $\mathrm{R}=\mathrm{Me}, 94 \%$ yield<smiles>CCO/C=C1\CCCC(/C=C/C2=C(C#N)C(=C(C#N)C#N)OC2(C)C)=C1Cl</smiles><smiles>CC(C#N)C1=C(C=CC2=C(Cl)C(=CC=C3CCCC(C#N)=C3C#N)CC2)C(C)(C)C(C)(C)O1</smiles>

Scheme 3: Synthetic routes to compounds $\mathrm{Ca}, \mathrm{Cb}$, and $\mathbf{C N a}$.

tained as iodine salts so that a counterion exchange could be carried out. Using this strategy, four "soft" salts could be obtained with a reaction yield ranging from $85 \%$ to $95 \%$ (see Scheme 5). It has to be noticed that this strategy has previously been reported in the literature $[17,18]$.

\section{Light absorption properties of the different NIR dyes}

The light absorption properties of the different proposed dyes are depicted in Figure 1. They are characterized by a sharp and intense absorption band in the NIR range. Remarkably, absorption of most of the dyes is excellent in the 700-850 nm spectral range, ensuring fairly good overlap with the emission spectrum of the laser diode used in this work (i.e., LD@785 nm). Interestingly, no effect of the counter anion was observed (some of the dyes with two different counter ions were prepared and compared). In each case, we observed that the maximum absorption wavelength depends on the structure of the dye and not of the counter anion: i) $\lambda_{\max }=798 \mathrm{~nm}$ for CBPh1 and CI1; ii) $\lambda_{\max }=$ $810 \mathrm{~nm}$ for CBPh2 and CI2; iii) $\lambda_{\max }=900 \mathrm{~nm}$ for CBPh3 and CI3; and iv) $\lambda_{\max }=780 \mathrm{~nm}$ for CBPh4 and CI4. However, the peripheral substituents in the cyanine scaffold play an important role in the absorption properties of some dyes, i.e., for CBPh3, CI3, and CI10 bearing a 1-hexyl-2-methylbenzo[cd] indol-1-ium unit: a bathochromic shift of $\approx 100 \mathrm{~nm}$ was found for these two dyes, as compared to the other dyes investigated in this work, absorbing up to $850 \mathrm{~nm}$. The latter, CBPh3, CI3, and CI10, exhibit a strong absorption above $850 \mathrm{~nm}(900-1000 \mathrm{~nm})$ and a relatively low absorption at $785 \mathrm{~nm}$ (wavelength of the irradiation used). The visible-NIR spectra of IR 813 (Scheme 2) considered as a reference is given in Figure S1 in Supporting Information File 1.

\section{NIR polymerization initiating ability}

Due to the good NIR absorption properties, the proposed dyes have been tested as photoinitiators in combination with an amine and an iodonium salt, iod, for the free radical polymerization of a benchmark acrylate monomer and compared to a reference initiating system based on IR 813 (Scheme 2) [7]. As the different dyes presented above exhibit good absorption properties at $785 \mathrm{~nm}$, the photoinitiating abilities of the threecomponent systems (NIR dye/iod/amine) based on these dyes were further investigated upon irradiation with a LD@785 nm.

Using DABA instead of NPG as the amine in the proposed three-component systems, the resulting polymerization profiles obtained with NPG and DABA, respectively, are depicted in Figure 2 and Figure 3. The NIR dyes proposed have strong abilities to initiate the free radical polymerization. Indeed, the polymers obtained are tack-free after only a few seconds of irradia- 

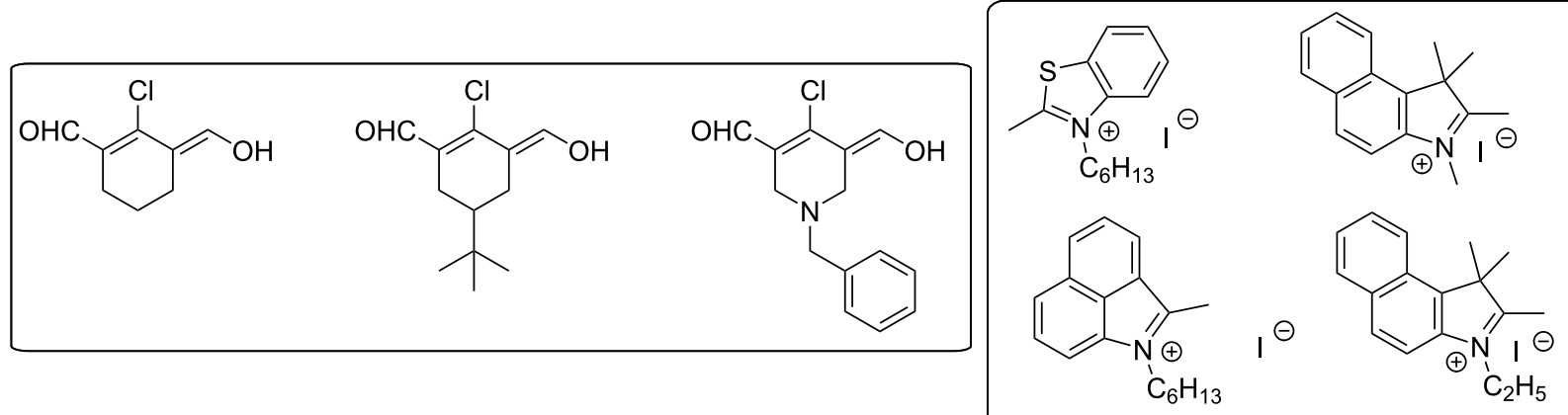
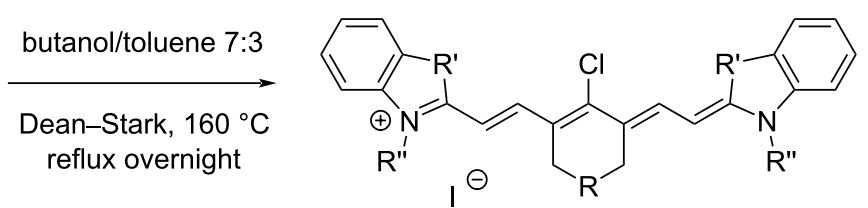<smiles>[R]C1CC(/C=C/C2=Nc3c(OC)cccc3C2(C)C)=C(Cl)/C(=C/C=C2\N(CC)c3ccccc3C2(C)C)C1</smiles>

Cl4: $\mathrm{R}=\mathrm{H}: 91 \%$ yield

Cl9: $R=t-B u: 84 \%$ yield

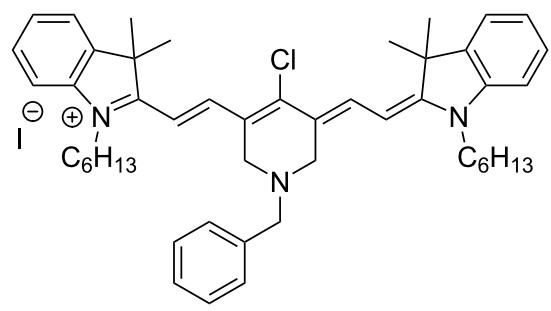

$86 \%$ yield

$\mathrm{Cl6}$<smiles>[R]N1C(/C=C/C2=C(Cl)/C(=C/C=C3\N([R])c4ccc5ccccc5c4C3(C)C)CC(C(C)(C)C)C2)=C(C)C(C)(C)c2c1ccc1ccccc21</smiles>

Cl7: $\mathrm{R}=\mathrm{Me}: 88 \%$ yield Cl8: $R=$ Et: $90 \%$ yield<smiles></smiles>

$82 \%$ yield

Cl1

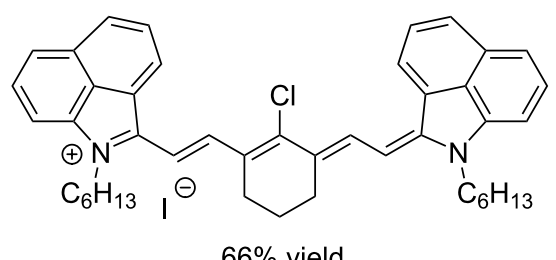

$66 \%$ yield

$\mathrm{Cl} 3$ tion (Scheme 6). Without NIR dyes, no polymerization occurs. At $785 \mathrm{~nm}$, in most cases, the final acrylate function conversion (FC) measured were higher than $80 \%$. Such a high reactive function conversion is quite high for multifunctional monomers (with PETIA being a trifunctional acrylic monomer). Moreover, for the majority of the proposed systems, the photo- polymerization starts as soon as the light is turned on. This can be explained by a low oxygen inhibition, which is an advantage for different applications where the photopolymerization under air is required. As shown in Figure 2 and Figure 3, only CNa, CBPh3, CI3, and CI10 show a long inhibition time, and this can be ascribed to the low absorption of these dyes at the wave- 


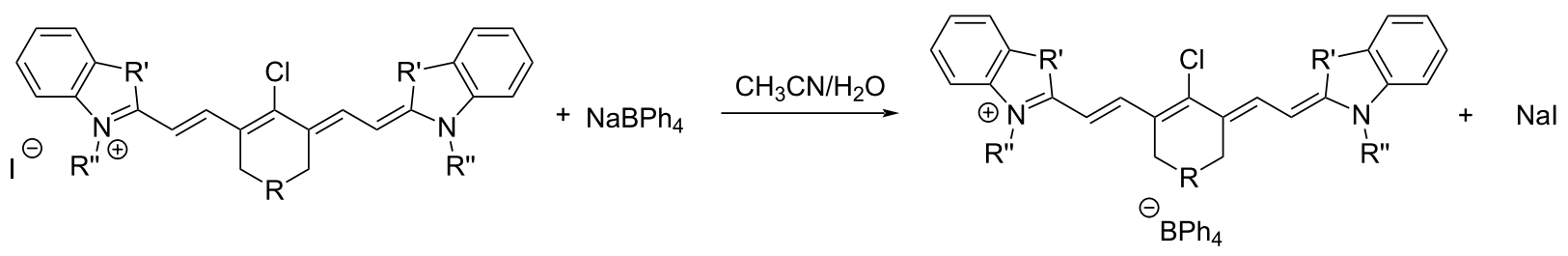<smiles></smiles>

CBPh1 $85 \%$ yield<smiles>CN1C(=CC=C2CCCC(C=CC3=[N+](C)c4ccc5ccccc5c43)=C2Cl)C(C)(C)c2c1ccc1ccccc21</smiles>

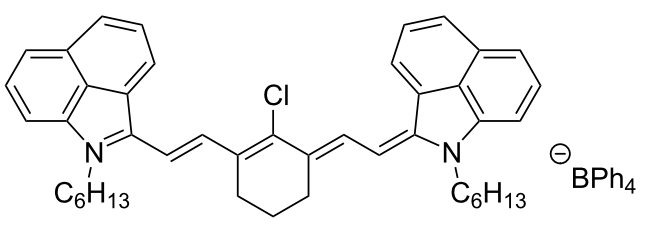

CBPh3 $88 \%$ yield

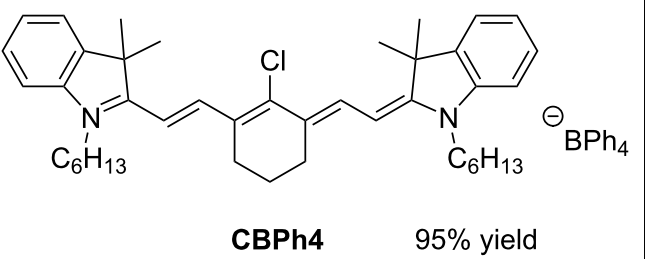

Scheme 5: The metathesis reaction enabling the formation of "soft" salts CBPh1-CBPh4

A)

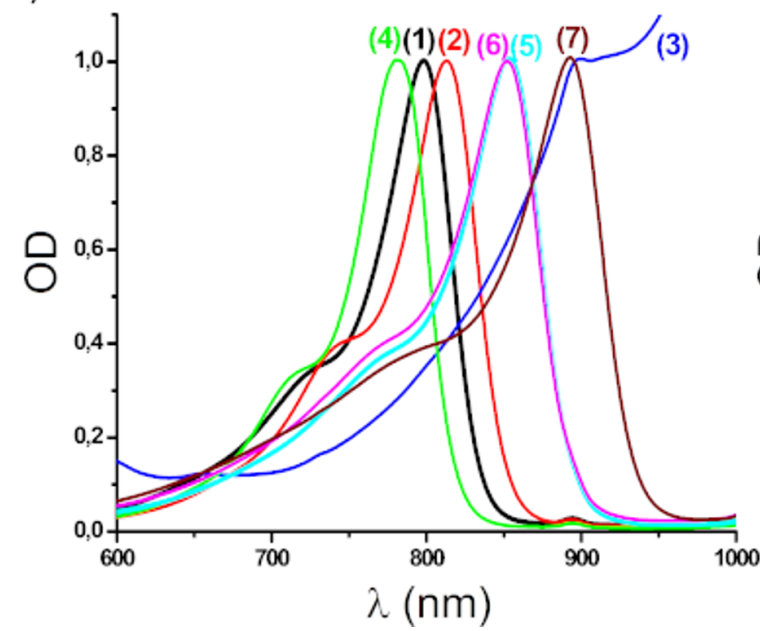

B)

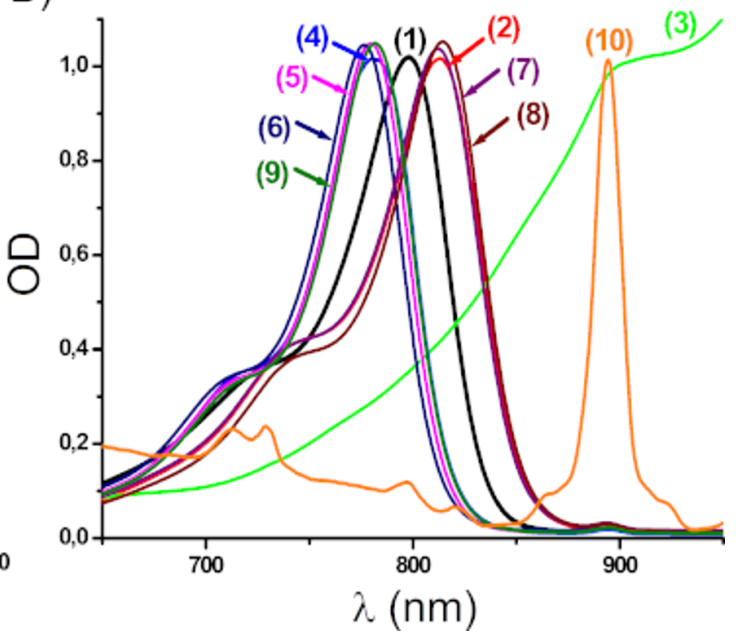

Figure 1: Visible-NIR spectra of NIR dyes in ACN. A) (1) CBPh1, (2) CBPh2, (3) CBPh3, (4) CBPh4, (5) Ca, (6) Cb, and (7) CNa. B) (1) Cl1, (2) Cl2, (3) $\mathrm{Cl3}$, (4) $\mathrm{Cl} 4$, (5) $\mathrm{Cl5}$, (6) Cl6, (7) $\mathrm{Cl}$, (8) $\mathrm{Cl} 8$, (9) $\mathrm{Cl9}$, and (10) Cl10.

length of the irradiation used here. However, despite the low absorptions at $785 \mathrm{~nm}$, the photopolymerization is still successful.

Interestingly, no major difference was observed between the two amines used (NPG as shown in Figure 2 vs DABA as shown in Figure 3). However, in most cases, while using DABA as the base, slightly higher final conversion could be reached, and the process was also more rapid (Table 1). Therefore, the amine structure has an influence on the polymerization process: the interaction existing between the dye and the amine is an important parameter governing the formation of 
A)

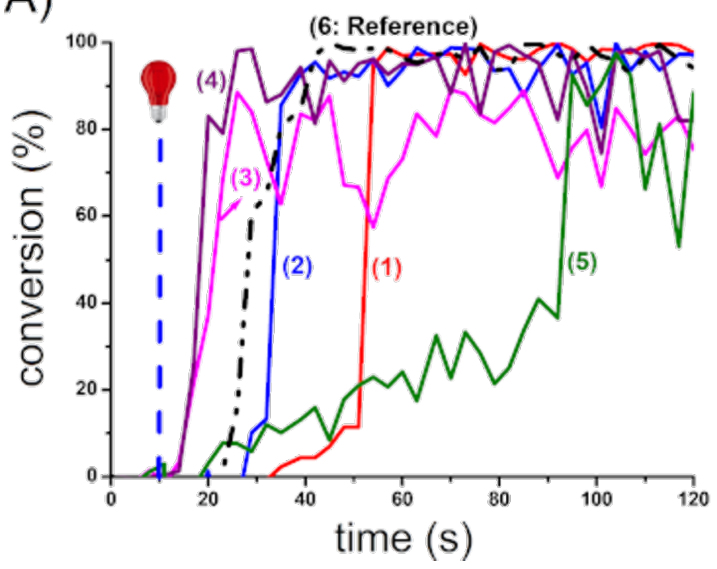

B)

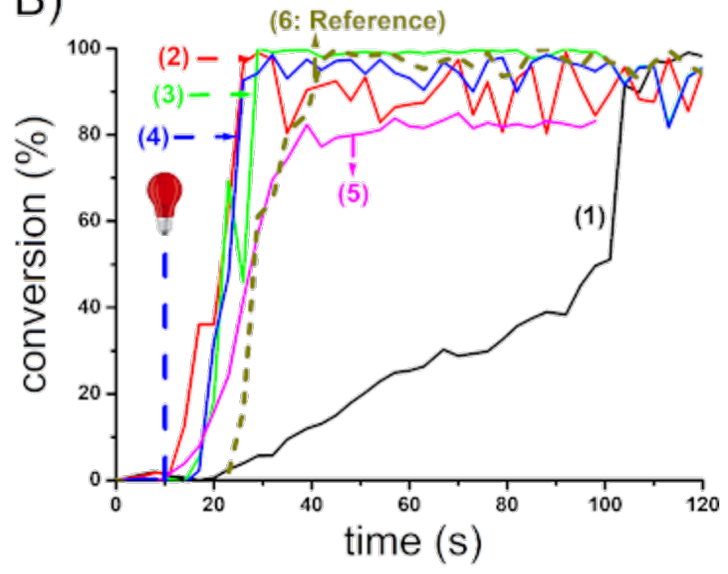

Figure 2: Photopolymerization profiles of PETIA monomer under air (acrylate functions conversion vs irradiation time) in the presence of a NIR dye/ iod/NPG 0.1:3:2. \%w/w/w system. A) NIR dyes with $\mathrm{BPh}_{4}{ }^{-}$and $\mathrm{Na}^{+}$as counter anion and counter cation: (1) $\mathbf{C a},(2) \mathbf{C b},(3) \mathbf{C B P h 1},(4) \mathbf{C B P h 4}$, (5) CNa, and (6) IR 813. B) NIR dyes with I- as counter anion: (1) Cl3, (2) Cl4, (3) Cl5, (4) Cl8, (5) Cl9, and (6) IR 813; upon exposure to a 785 nm laser diode $\left(0.9 \mathrm{~W} / \mathrm{cm}^{2}\right)$, thickness $=1.4 \mathrm{~mm}$. The irradiation starts at $t=10 \mathrm{~s}$.
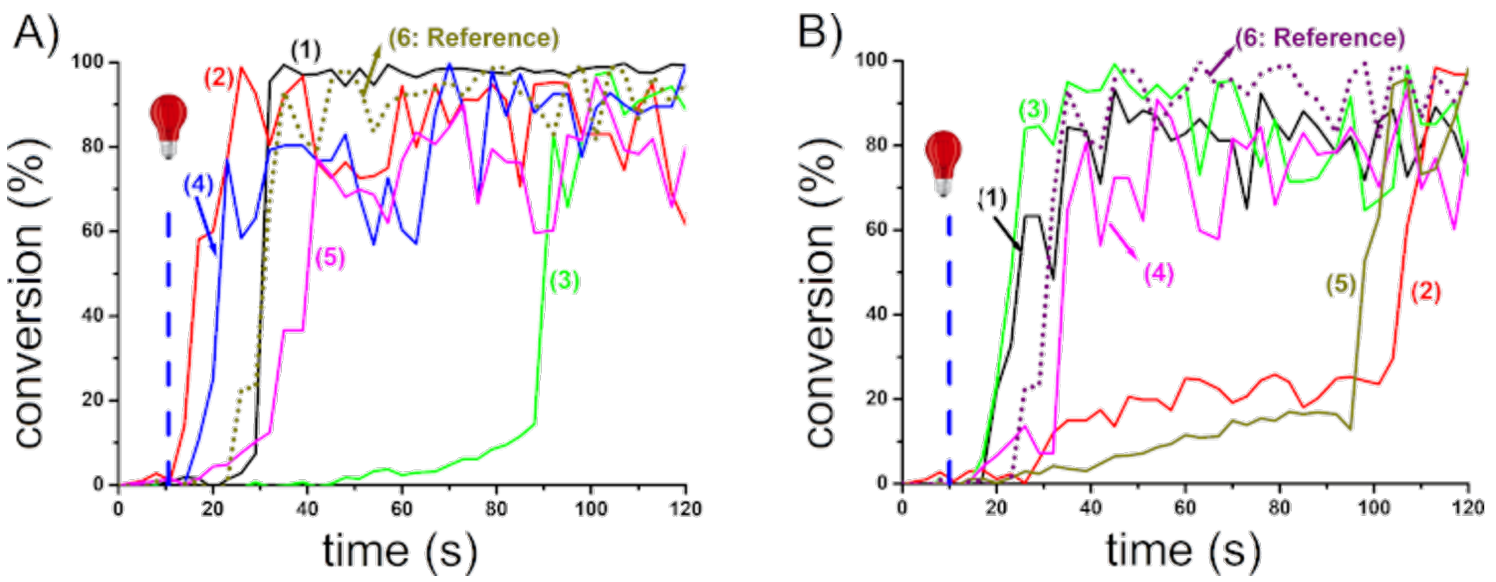

Figure 3: Photopolymerization profiles of PETIA monomer under air (acrylate functions conversion vs irradiation time) in the presence of a NIR dye/ iod/DABA 0.1:3:2, \%w/w/w system. A) NIR dyes with $\mathrm{BPh}_{4}{ }^{-}$and $\mathrm{Na}^{+}$as counter anion and counter cation: (1) Cb, (2) CBPh1, (3) CBPh3, (4) CBPh4, (5) $\mathbf{C N a}$, and (6) IR 813. B) NIR dyes with I- as counter anion: (1) Cl1, (2) Cl3, (3) Cl5, (4) Cl9, (5) Cl10, and (6) IR 813; upon exposure to a 785 nm laser diode $\left(0.9 \mathrm{~W} / \mathrm{cm}^{2}\right)$, thickness $=1.4 \mathrm{~mm}$. The irradiation starts at $t=10 \mathrm{~s}$.

initiating radicals. The slightly lower reactivity of NPG vs DABA can probably be ascribed to a lower production of initiating radicals in this case, rendering the associated PIS slightly less efficient to overcome the oxygen inhibition. This behavior has already been observed in other works when other NIR dyes were used in three-component PISs comprising an oxidant agent and an amine [8]. In all cases, NIR dyes proposed showed excellent reactivity using different amines and an iodonium salt. This suggests that an NIR approach is an elegant way for fast curing processes upon mild irradiation conditions (much longer wavelength than UV light).
As shown in the Scheme 1, the dyes investigated in this work differ by the counter anion and cation, respectively. By taking into account the effect of the counter ion, the trend in efficiency follows the order $\mathrm{BPh}_{4}{ }^{-}>\mathrm{I}^{-}>\mathrm{Na}^{+}$. The polymerization is much more efficient when borate is used as the counter anion with both a higher polymerization rate and FC. The results show that the formation of initiating radicals can be related to the decomposition of the borate moiety. This can be explained by the fact that the borate counter ion can act as an electron-donating component with the radical cation dye $e^{\bullet+}$ and therefore, the dye/borate system is able to generate additional free radi- 
A)
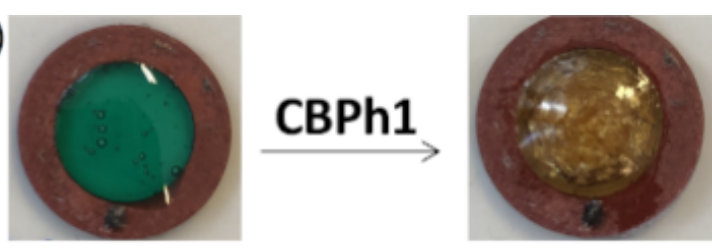

B)
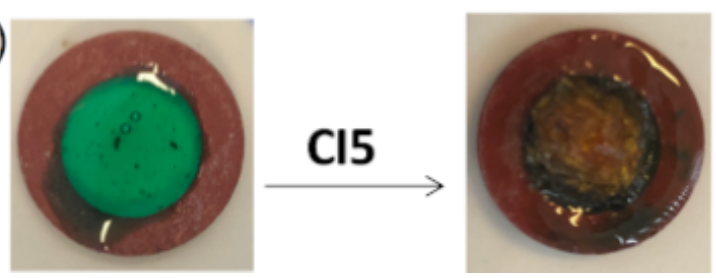

Scheme 6: Pictures of polymers obtained for a thickness of $1.4 \mathrm{~mm}$, using a NIR dye/iod/amine 0.1:3:2, \%w/w/w system. A) amine $=\mathrm{NPG}$ and $\mathrm{B}$ ) amine = DABA; upon exposure to a $785 \mathrm{~nm}$ laser diode $\left(0.9 \mathrm{~W} / \mathrm{cm}^{2}\right)$ for 120 seconds under air.

cals in the reaction medium, improving, in turn, the polymerization process (Scheme 7). This behavior has already been reported in the literature and is in full agreement with the proposed mechanism [4].

More particularly, it is interesting to compare the new proposed dye with IR 813 , used as a benchmark structure. Under the same conditions, many dyes show a reactivity similar to IR 813 . We noticed that IR 813 shows an excellent reactivity in NIR photopolymerization [7]. Remarkably, in this work, no inhibition time was observed while using different dyes, i.e., CBPh1, CBPh4; CI1, and CI5, as compared to IR 813. All these observations suggest that the proposed photoinitiating NIR dye/iod/ amine compositions result in high-performance NIR-photosensitive systems.

Polymerization of an acrylate-based monomer causes the release of heat from each polymerizing double bond $(-83.6 \mathrm{~kJ} / \mathrm{mol})$ [19]. This allows an exothermic reaction in different systems based on the reactivity but also due to the heater behavior of the NIR dye, i.e., a high light-to-heat (photothermal) conversion process is expected with different NIR dyes [9]. Table 1 and Figure S2 (Supporting Information File 1) clearly show the exothermicity observed upon irradiation.

The proposed NIR dye/iodonium combinations are able to generate free radicals and cationic species (Scheme 7 and Figure 4), and these two-component systems can also be used for the preparation of IPNs through the polymerization of acrylate/epoxy monomer blends (3,4-epoxycyclohexylmethyl-3,4epoxycyclohexane carboxylate from Allnex was used as benchmark epoxy monomer) [20]. The formation of IPNs can be

\begin{tabular}{|c|c|c|c|c|c|}
\hline \multirow[t]{2}{*}{ category } & \multirow[t]{2}{*}{ compound } & \multicolumn{2}{|c|}{ NPG } & \multicolumn{2}{|c|}{ DABA } \\
\hline & & curing time ${ }^{a}$ & exothermicity ${ }^{b}$ & curing time & exothermicity \\
\hline \multirow[t]{2}{*}{ no counter ion } & $\mathrm{Ca}$ & $97 \%$ in $55 \mathrm{~s}$ & ++ & $40 \%$ in $>120 \mathrm{~s}$ & + \\
\hline & $\mathrm{Cb}$ & $96 \%$ in $41 \mathrm{~s}$ & ++ & $97 \%$ in 35 s & ++ \\
\hline $\mathrm{Na}^{+}$as counter cation & $\mathrm{CNa}$ & $90 \%$ in $95 \mathrm{~s}$ & ++ & $80 \%$ in $42 \mathrm{~s}$ & + \\
\hline \multirow[t]{4}{*}{ borate as counter anion } & CBPh1 & $87 \%$ in $26 \mathrm{~s}$ & + & $92 \%$ in $18 \mathrm{~s}$ & + \\
\hline & CBPh2 & $-c$ & - & $90 \%$ in $26 \mathrm{~s}$ & ++ \\
\hline & CBPh3 & $50 \%$ in $>120 \mathrm{~s}$ & + & $95 \%$ in $100 \mathrm{~s}$ & + \\
\hline & CBPh4 & $97 \%$ in $27 \mathrm{~s}$ & ++ & $89 \%$ in $36 \mathrm{~s}$ & ++ \\
\hline \multirow[t]{10}{*}{$I^{-}$as counter anion } & $\mathrm{Cl1}$ & $40 \%$ in $>120 \mathrm{~s}$ & + & $84 \%$ in $35 \mathrm{~s}$ & + \\
\hline & $\mathrm{Cl} 2$ & $-^{c}$ & - & $92 \%$ in $34 \mathrm{~s}$ & + \\
\hline & $\mathrm{Cl} 3$ & $95 \%$ in $110 \mathrm{~s}$ & ++ & $97 \%$ in $113 \mathrm{~s}$ & ++ \\
\hline & $\mathrm{Cl} 4$ & $99 \%$ in $26 \mathrm{~s}$ & + & $60 \%$ in $>120 \mathrm{~s}$ & + \\
\hline & $\mathrm{Cl5}$ & $99 \%$ in $29 \mathrm{~s}$ & ++ & $95 \%$ in $34 \mathrm{~s}$ & + \\
\hline & $\mathrm{Cl} 6$ & $90 \%$ in $34 \mathrm{~s}$ & + & $90 \%$ in $50 \mathrm{~s}$ & ++ \\
\hline & $\mathrm{Cl} 7$ & $40 \%>120 s$ & + & $40 \%$ in $>120 \mathrm{~s}$ & + \\
\hline & $\mathrm{Cl}$ & $95 \%$ in $26 \mathrm{~s}$ & ++ & $84 \%$ in $45 \mathrm{~s}$ & + \\
\hline & Cl9 & $94 \%$ in $32 \mathrm{~s}$ & + & $90 \%$ in $45 \mathrm{~s}$ & + \\
\hline & Cl10 & $10 \%$ in $>120 \mathrm{~s}$ & + & $92 \%$ in $105 \mathrm{~s}$ & ++ \\
\hline reference compound & IR 813 & $97 \%$ in $43 \mathrm{~s}$ & ++ & $97 \%$ in $37 \mathrm{~s}$ & ++ \\
\hline
\end{tabular}

aTime required to reach high final conversion. ${ }^{b_{+}}$: steams; ++: steams and cracks. ${ }^{c}$ Not stable: polymerization upon stirring. 


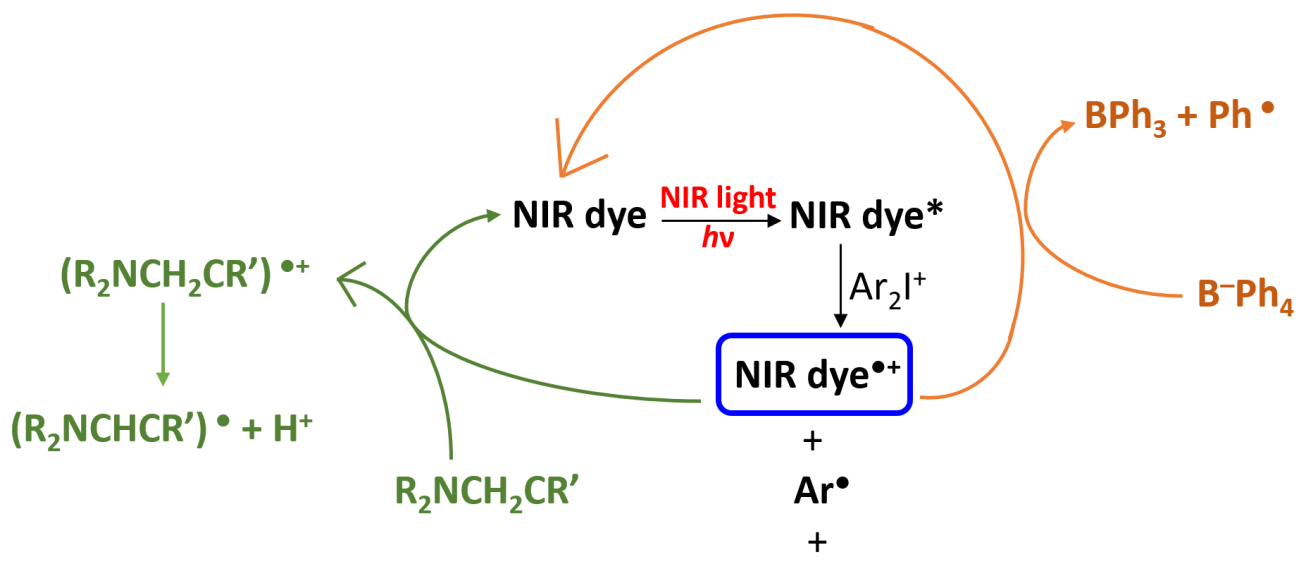

Arl

A)

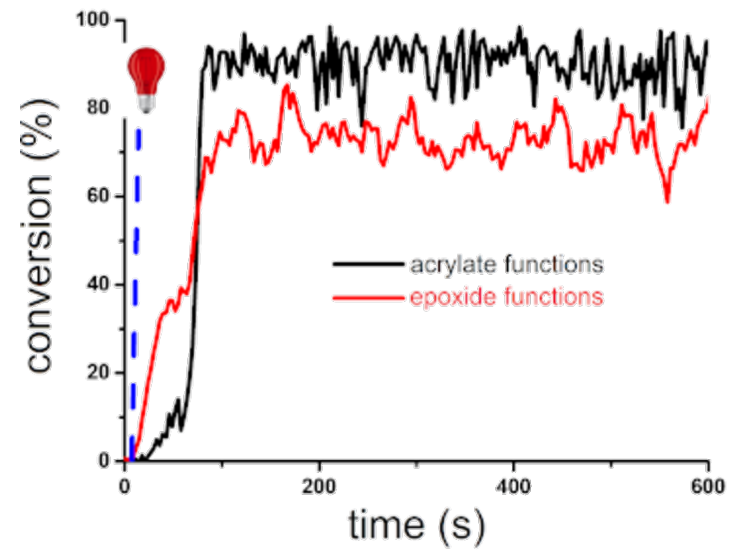

B)

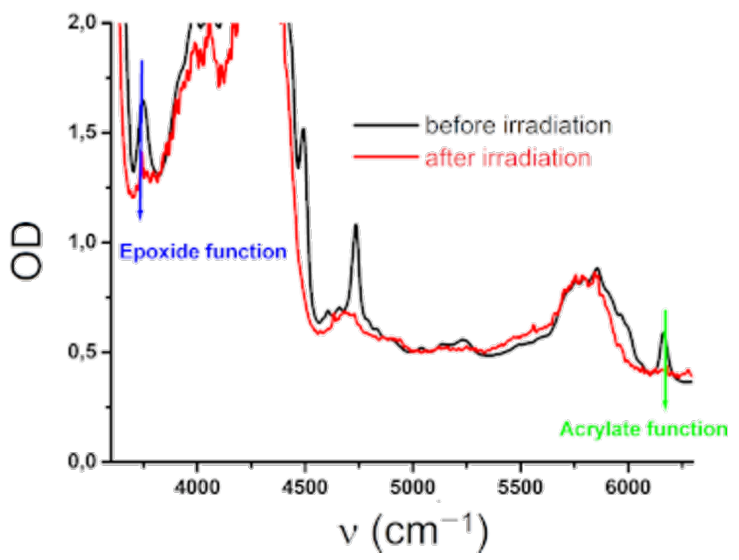

Figure 4: A) Photopolymerization profiles of PETIA/epoxy blend 1:1, w/w under air (acrylate and epoxy functions conversion vs irradiation time) in the presence of $\mathbf{C b} /$ iod 0.3:2, w/w upon exposure to a laser diode at $785 \mathrm{~nm}\left(0.9 \mathrm{~W} / \mathrm{cm}^{2}\right)$, thickness $=1.4 \mathrm{~mm}$. The irradiation starts at $t=10 \mathrm{~s}$. B) $\mathrm{FTIR}$ spectra before and after irradiation.

highly worthwhile to reach better polymer mechanical properties or lower shrinkage than pure radical polymerization.

\section{Conclusion}

In the present study, a number of NIR-absorbing dyes has been investigated as potential NIR PISs. The NIR curing of acrylate monomer is proposed in the presence of three-component PISs (NIR dye/iod/amine). The free radical polymerization upon exposure to the laser diode at $785 \mathrm{~nm}$ was successfully initiated using new synthesized dyes. This can be used to obtain tackfree polymers after only a few seconds of NIR irradiation. Markedly, IPNs can also be prepared with NIR light. Potential applications and investigations of the mechanical properties of the generated polymers and composites will be provided in the forthcoming works.

\section{Supporting Information}

\section{Supporting Information File 1}

Additional figures and experimental data.

[https://www.beilstein-journals.org/bjoc/content/

supplementary/1860-5397-17-133-S1.pdf] 


\section{Acknowledgements}

We thank Lucie Schiavo and Gwendoline Lejeune for the scientific discussions.

\section{Funding}

We are grateful to SATT Conectus for the funding of this work.

\section{ORCID ${ }^{\circledR}$ iDs}

Guillaume Noirbent - https://orcid.org/0000-0002-3547-0278

Frédéric Dumur - https://orcid.org/0000-0003-4872-094X

Jacques Lalevée - https://orcid.org/0000-0001-9297-0335

\section{References}

1. Kirschner, J.; Szillat, F.; Bouzrati-Zerelli, M.; Becht, J.-M.; Klee, J. E.; Lalevée, J. J. Polym. Sci., Part A: Polym. Chem. 2019, 57, 1664-1669. doi:10.1002/pola.29431

2. Kirschner, J.; Paillard, J.; Bouzrati-Zerelli, M.; Becht, J.-M.; Klee, J. E.; Chelli, S.; Lakhdar, S.; Lalevée, J. Molecules 2019, 24, 2913. doi:10.3390/molecules24162913

3. Schmitz, C.; Strehmel, B. ChemPhotoChem 2017, 1, 26-34. doi:10.1002/cptc.201600009

4. Strehmel, B.; Brömme, T.; Schmitz, C.; Reiner, K.; Ernst, S.; Keil, D. NIR-Dyes for Photopolymers and Laser Drying in the Graphic Industry. In Dyes and Chromophores in Polymer Science; Lalevée, J.; Fouassier, J. P., Eds.; John Wiley \& Sons: Hoboken, NJ, USA, 2015; pp 213-249. doi:10.1002/9781119006671.ch7

5. Karatsu, T.; Yanai, M.; Yagai, S.; Mizukami, J.; Urano, T.; Kitamura, A. J. Photochem. Photobiol., A 2005, 170, 123-129. doi:10.1016/j.jphotochem.2004.08.010

6. Schmitz, C.; Halbhuber, A.; Keil, D.; Strehmel, B. Prog. Org. Coat. 2016, 100, 32-46. doi:10.1016/j.porgcoat.2016.02.022

7. Bonardi, A. H.; Dumur, F.; Grant, T. M.; Noirbent, G.; Gigmes, D.; Lessard, B. H.; Fouassier, J.-P.; Lalevée, J. Macromolecules 2018, 51, 1314-1324. doi:10.1021/acs.macromol.8b00051

8. Mokbel, H.; Graff, B.; Dumur, F.; Lalevée, J. Macromol. Rapid Commun. 2020, 41, 2000289 doi:10.1002/marc.202000289

9. Bonardi, A.-H.; Bonardi, F.; Morlet-Savary, F.; Dietlin, C.; Noirbent, G.; Grant, T. M.; Fouassier, J.-P.; Dumur, F.; Lessard, B. H.; Gigmes, D.; Lalevée, J. Macromolecules 2018, 51, 8808-8820. doi:10.1021/acs.macromol.8b01741

10. Brömme, T.; Schmitz, C.; Moszner, N.; Burtscher, P.; Strehmel, N.; Strehmel, B. ChemistrySelect 2016, 1, 524-532. doi:10.1002/slct.201600048

11. Schmitz, C.; Strehmel, B. J. Coat. Technol. Res. 2019, 16, 1527-1541. doi:10.1007/s11998-019-00197-3

12. Shiraishi, A.; Kimura, H.; Oprych, D.; Schmitz, C.; Strehmel, B. J. Photopolym. Sci. Technol. 2017, 30, 633-638. doi:10.2494/photopolymer.30.633

13. Strehmel, B.; Schmitz, C.; Brömme, T.; Halbhuber, A.; Oprych, D.; Gutmann, J. S. J. Photopolym. Sci. Technol. 2016, 29, 111-121. doi:10.2494/photopolymer.29.111

14. Shimada, K.; Sorori, T.; Yagihara, M. Photosensitive Composition and Planographic Printing Plate Precursor. Eur. Patent EP1449650B1, Aug 25, 2004

15. Fabian, J.; Nakazumi, H.; Matsuoka, M. Chem. Rev. 1992, 92 , 1197-1226. doi:10.1021/cr00014a003
16. Lalevée, J.; Blanchard, N.; Tehfe, M.-A.; Peter, M.; Morlet-Savary, F.; Fouassier, J. P. Macromol. Rapid Commun. 2011, 32, 917-920. doi:10.1002/marc.201100098

17. Dumur, F.; Nasr, G.; Wantz, G.; Mayer, C. R.; Dumas, E.; Guerlin, A.; Miomandre, F.; Clavier, G.; Bertin, D.; Gigmes, D. Org. Electron. 2011, 12, 1683-1694. doi:10.1016/j.orgel.2011.06.014

18. Nasr, G.; Guerlin, A.; Dumur, F.; Beouch, L.; Dumas, E.; Clavier, G.; Miomandre, F.; Goubard, F.; Gigmes, D.; Bertin, D.; Wantz, G.; Mayer, C. R. Chem. Commun. 2011, 47, 10698. doi:10.1039/c1cc13733f

19. Tryson, G. R.; Shultz, A. R. J. Polym. Sci., Polym. Phys. Ed. 1979, 17, 2059-2075. doi:10.1002/pol.1979.180171202

20. Pang, Y.; Shiraishi, A.; Keil, D.; Popov, S.; Strehmel, V.; Jiao, H.; Gutmann, J. S.; Zou, Y.; Strehmel, B. Angew. Chem., Int. Ed. 2021, 60, 1465-1473. doi:10.1002/anie.202010746

\section{License and Terms}

This is an Open Access article under the terms of the Creative Commons Attribution License (https://creativecommons.org/licenses/by/4.0). Please note that the reuse, redistribution and reproduction in particular requires that the author(s) and source are credited and that individual graphics may be subject to special legal provisions.

The license is subject to the Beilstein Journal of Organic Chemistry terms and conditions: (https://www.beilstein-journals.org/bjoc/terms)

The definitive version of this article is the electronic one which can be found at: https://doi.org/10.3762/bjoc.17.133 